\title{
Navicular stress fracture injury: observational use of plantar pressure measures in elite AFL footballers
}

\author{
Ian North ${ }^{1,2^{*}}$, Laurence Foley ${ }^{3}$ \\ From Australasian Podiatry Council Conference 2013 \\ Sydney, Australia. 2-5 June 2013
}

\section{Results}

Analysis of the derived variables demonstrated distinct asymmetries in plantar foot loading in both subjects. Between-subject similarities exist in terms of elevated Peak Pressure $(\mathrm{kPa})$ beneath the $2^{\text {nd }}$ metatarsophalangeal joint on the injured limb. Subject 1 , demonstrates a deviation between the $1^{\text {st }}$ and $2^{\text {nd }}$ digit as a consequence of metatarsus primus adductus. Plantar pressure mapping depicted relative length differentials between the hallux and $2^{\text {nd }}$ digits on both subjects injured limbs. Subject 2 demonstrates asymmetry in pressure time curves between injured and non injured feet with a pronounced initial impact peak on the injured side. The implication of this in terms of injury risk is unclear.

\section{Conclusions}

Presented is the use of plantar pressure mapping in NSF injury in two Elite AFL footballers. The results suggest increased FF pressure and anatomical variations such as a short 1st metatarsal and metatarsus adductus could contribute to NSF injury. Technology such as plantar pressure mapping may be used prospectively to assess or screen at risk groups for NSF injury.

\section{Author details}

${ }^{1}$ Willetton Podiatry Clinic, Willetton, Western Australia, 6155, Australia.

${ }^{2}$ Fremantle Football Club, Fremantle, Western Australia, 6931, Australia.

${ }^{3}$ Podiatric Medicine Unit, School of Surgery, University of Western Australia,

Nedlands, Western Australia, 6009, Australia.

Published: 31 May 2013

doi:10.1186/1757-1146-6-S1-P11

Cite this article as: North and Foley: Navicular stress fracture injury: observational use of plantar pressure measures in elite AFL footballers. Journal of Foot and Ankle Research 2013 6(Suppl 1):P11.

* Correspondence: willettonpodiatry@gmail.com

'Willetton Podiatry Clinic, Willetton, Western Australia, 6155, Australia

Full list of author information is available at the end of the article 